\title{
Impact of Smoking on Women During the Covid-19 Pandemic
}

\author{
Florin Dumitru Mihaltan ${ }^{1}$, Armand-Gabriel Rajnoveanu ${ }^{2 \star}$ and \\ Ruxandra-Mioara Rajnoveanu ${ }^{3}$
}

${ }^{1}$ Pneumology Department, Marius Nasta National Institute of Pneumology, Bucharest, Romania, ${ }^{2}$ Occupational Medicine Department, Iuliu Hatieganu University of Medicine and Pharmacy, Cluj-Napoca, Romania, ${ }^{3}$ Pneumology Department, Iuliu Hatieganu University of Medicine and Pharmacy, Cluj-Napoca, Romania

\section{OPEN ACCESS}

Edited by:

Dragana Jovanovic,

University of Belgrade, Serbia

Reviewed by:

Mateusz Zatonski,

University of Bath, United Kingdom Joanna Julia Domagala-Kulawik, Medical University of Warsaw, Poland

${ }^{*}$ Correspondence: Armand-Gabriel Rajnoveanu armand.rajnoveanu@umfcluj.ro

Specialty section:

This article was submitted to Pulmonary Medicine,

a section of the journal Frontiers in Medicine

Received: 16 July 2020 Accepted: 09 March 2021

Published: 30 April 2021

Citation:

Mihaltan FD, Rajnoveanu A-G and Rajnoveanu R-M (2021) Impact of Smoking on Women During the

Covid-19 Pandemic.

Front. Med. 8:584061.

doi: 10.3389/fmed.2021.584061
The coronavirus disease 2019 (COVID-19) brought in 2020 an important challenge for health-care systems and authorities. Smoking and its influence on this disease remain, after months of the pandemic, one of the debatable risk factors. From the literature point of view, the focus of most articles is on smoking as a possible general risk factor for all analyzed populations. Women tend to represent a more significant population in exposed occupations. In our mini-review, we try to dig deeper, looking for gender-related health effects of smoking in this pandemic context, its effects on the infection with this novel severe acute respiratory syndrome coronavirus 2 (SARS-CoV-2), on illness severity, and on the rate of hospitalization and mortality. Despite the fact that the male gender is reported in many articles as a predictor of a poor outcome, we suggest that further research is needed to confirm or deny these relationships. Moreover, studies focusing specifically on women in these study populations are required.

Keywords: women, smoking, COVID-19, pandemic, SARS-CoV-2, gender, sex

\section{INTRODUCTION}

The coronavirus disease 2019 (COVID-19) is a new global threat. It started in December 2019 in Wuhan, China, and the novel coronavirus was identified on January 7, 2020 in a patient with pneumonia and severe acute respiratory syndrome (SARS) (1). Smoking is considered a risk factor for COVID-19 patients, which increases the susceptibility to bacterial and viral infections in a multifactorial way (by the alteration of muco-ciliary escalator and immunological defense mechanisms) and enhances inflammation in a lung already affected by structural and immunological alterations (2). Tobacco consumption also increases the expression of angiotensin-converting enzyme 2 (ACE-2), which is a binding receptor for severe acute respiratory syndrome coronavirus 2 (SARS-CoV-2) (3). Some previous evidence related to smoking as a risk factor came from studies focused on the vulnerability of patients with smoking history to influenza and other coronavirus infections like the Middle East respiratory syndrome (MERS)-related coronavirus $(4,5)$. The focus on women who smoke is important and well-justified in reference to their professional profiles and roles as caregivers in some countries, which may make them more vulnerable to the impact of COVID-19.

We conducted a systematic mini-review and meta-analysis considering the association of smoking with SARS-CoV-2 infection or COVID-19 based on electronic search in MEDLINE (PubMed interface), Scopus, and Web of Science using the keywords "smoking" AND "COVID-19," OR "2019-nCoV," OR "SARS-CoV-2," without language or time restriction. To collect maximum data, we did not limit the search to gender-related articles. The abstract and full text of all 
documents identified with these search criteria were reviewed to identify information on gender-related aspects of smoking and COVID-19.

\section{Smoking and COVID-19: An Active Debate}

COVID-19 does not seem to affect patients uniformly. There are studies that found nearly similar infection rates in both genders (6), while others like the extensive meta-analysis on 221,195 patients published recently in BMJ Open, revealed a pooled prevalence of COVID-19 among men aged 55.00 years (range, 51.43-56.58, $p<0.001$ ), with smoking and alcohol consumption being suggested as possible explanations (7). Another metaanalysis on 233 studies that looked at the impact of smoking reported some surprising results: current smokers appear to be at a reduced risk of SARS-CoV-2 infection compared to never smokers (8). Similar findings were published by Farsalinos et al. (9) through the analysis of the pooled prevalence of the current smoking status across 11 case series of Chinese patients. The current smoking status had a significantly lower-than-expected gender and age-adjusted prevalence in COVID-19 patients. Italian authors, without any comments on gender influences (10), also reported that $84.8 \%$ of Italian patients with COVID19 pneumonia never smoked, and $15.2 \%$ were ex-smokers, in the Veneto region, with a prevalence of $22.4 \%$ smokers and $21.2 \%$ ex-smokers.

Looking more in-depth at smoking and COVID-19 relationship, a meta-analysis on 31,871 patients revealed a positive association between smoking and disease progression [29.2\% in smokers and $21.1 \%$ in non-smokers with an odds ratio (OR): $1.56,95 \%$ confidence interval (CI): $1.32-1.83, p=0.001$ ]. Moreover, the same research showed that smoking seems to be an independent risk factor for COVID-19 progression especially in younger people (11). These findings are confirmed by Spanish researchers (12) who concluded that current and past smoking are responsible for more severe forms of COVID-19, including more cases treated in intensive care units, intubations, and even death. Smoking was cited in the list of characteristics associated with severe SARS-CoV-2 infection (OR: 1.54, 95\% CI 1.07-2.22), alongside cerebrovascular and cardiovascular disease, chronic obstructive pulmonary disease (COPD), diabetes, hypertension, and the male sex (13).

Apparently, in the US, there were $15.6 \%$ male and $12 \%$ female smokers in the general population in 2018 with a $1.3 \%$ prevalence for COVID-19 in current smoker patients (14). In China, there is a $1.4 \%$ prevalence of COVID-19 in current smoker patients vs. the prevalence of smoking in general population (52\% in males and $2.5 \%$ in females) (15). However, there are many limitations to these studies, including small study populations, only inpatients as subjects, no age- and sexmatched control groups, or a high rate of missing data. Other limitations are generated by the percentage of asymptomatic patients. Furthermore, identifying asymptomatic infections is difficult, which makes it difficult to prevent and control this pandemic and understand the relationship of smoking habits in these populations (16). French studies sustaining the nicotinic hypothesis $(17,18)$ reported other interesting gender-related details that there are no statistical differences when it comes to comorbidities in inpatients and outpatients at different age groups. The only statistical gender-related differences are for diabetes, immunodeficiency, and hypertension. However, these studies are problematic because neither study is peer reviewed. The lead author of the first one has a deep and long-standing link to the tobacco industry and proposes a new hypothesis inconsistent with the broader emerging literature on the links between smoking and COVID-19 (19). The second study was based on results from one small hospital where patients were not representative of the larger population and excluded intensive care and asymptomatic patients (19).

These results that showed lower prevalence of smoking in COVID-19 patients compared to the general population suggested the protective role of nicotine. A possible explanation was formulated by Abdel Massih et al., which was based on the decreasing effect of smoking on cellular levels of furin, a cleavage enzyme increasingly recognized in the pathogenesis of metabolic syndrome, and found in high serum levels of obese and diabetic patients (20).

\section{Smoking, Gender, and Hospitalization for COVID-19}

Authors of 27 observational studies found that smokers represented 1.4-18.5\% of hospitalized adults with COVID19 (14, 21, 22). In The New England Journal of Medicine article published by Guan et al. titled, "Clinical Characteristics of Coronavirus Disease 2019 in China" (23), it showed that compared to non-smokers, smokers are 2.4 times more likely to be admitted to an intensive care unit, require mechanical ventilation, or die, with no gender-related correlation being studied. Smoking (ex-smokers, in particular) was associated with greater risk of COVID-19 hospitalization (24).

In a United Kingdom study, the lifestyle characteristics impact on patients hospitalized for viral infection $(0.2 \%$ of the whole study group) compared to an analytical population of 387,109 participants ( $56.2 \pm 8.0$ years; $55.1 \%$ women), found a risk ratio adjusted for age, gender, and mutually for each lifestyle factor (including smoking) of 1.42 (1.79 vs. 1.12) (25).

A New York City research on factors associated with hospital admission revealed the male sex (OR: 2.8, 95\% CI: 2.4-3.2, average marginal effect $16 \%$ ) as a predictor, alongside age, heart failure, and chronic kidney disease (26). Another interesting finding of this article was the lower risk for hospital admission of former or current smokers; however, unknown smoking status was associated with a higher risk, and this may indicate a major bias that may arise in these studies.

\section{Smoking, Gender, and COVID-19 Severity}

The presence of comorbidities may play an important role in disease progression. They are associated with a substantially increased risk of severe prognosis (27). Chinese studies provide a strong evidence regarding the association that male COVID19 patients have higher rates of comorbidities than women $(15,23,28)$. These comorbidities with higher rates in Chinese men compared to women are as follows: type 2 diabetes mellitus, arterial hypertension, COPD, lung cancer, and other smoking-related diseases (27). Some authors estimated 6\% [with 
uncertainty interval (UI): 3-12] of males to be at high risk of severe COVID-19 infections compared to $3 \%$ (UI: $2-7$ ) of females (29). The prevalence of one or more comorbidities depends on age, with approximately $10 \%$ by the age of 25 years, $33 \%$ by the age of 50 years, and $66 \%$ by the age of 70 years, similar for both males and females (29). Compared to non-smokers, smokers who are hospitalized with COVID-19 have two to nine times higher risk of serious COVID-19 complications (30). This relationship is not evident for women. Studies that searched for correlations between different comorbidities and COVID-19 reported that most female cases with rheumatic diseases and COVID-19 were hospitalized, and patients were in the 50-65 years age group and were non-smokers (389 subjects, representing 75\%) (31). Some authors that do not acknowledge the relationship between smoking and SARS-CoV-2 infection severity (32). Lippi et al. do not consider active smoking as a significant predictor of COVID-19 severity, based on a meta-analysis performed on data collected from four Chinese studies, but they admit the existence of an appreciable trend toward a higher risk of severe disease progression associated with active smoking. A strong evidence of smoking as a predictor for a severe outcome is revealed by a meta-analysis performed on 22 studies and 13,184 COVID-19 patients (33). Current smoking (OR: 1.98; 95\% CI: 1.16-3.39) and former smoking (OR: 3.46; 95\% CI: 2.46-4.85) were associated with severe diseases. Most of the included studies were completed in China (95\%), and 55\% of participants were males, but no data on gender statistics were reported. Similar results were published by Reddy et al. on patients with a smoking history, analyzing data of 47 eligible studies and 32,849 patients (34), but without gender-related data.

Although it is premature to assess all the aspects of serious and late complications of COVID-19, such as pulmonary fibrosis, some initial findings may be reported, with smoking as one of the possible predictors of progression (35).

\section{Smoking, Gender, and Mortality by COVID-19}

Evidence from previous reports suggested a higher mortality by SARS and MERS in male patients. Smoking, genetic factors, and the impact of reproductive hormones on immune systems and inflammatory responses were investigated as implicated in this gender disparity (36). Regarding COVID-19, a significant positive relationship between death and smoking or former smoking was found by Williamson et al. They examined 17 million patient records to determine risk factors for 5,683 COVID-19 fatalities (37). This was valuable only when the statistical model was adjusted for age and sex. Mortality due to SARS-CoV-2 in China was higher among men $(4.7 \%)$ than women $(2.8 \%)$, which may also reflect the large sex differences in smoking habits in China (52.1\% in men and $2.7 \%$ in women) $(38,39)$. For Western countries, although the prevalence of smoking in men were higher, the gender differences in mortality due to COVID-19 were not that high (40). Spanish authors reported similar rates of COVID-19 prevalence of 50.4 and $49.9 \%$ in men and women, respectively, but with a mortality rate of 4.7 and $2.6 \%$, respectively. This was explained by gender-based differences, such as patterns and prevalence of smoking. In Spain, tobacco smoking prevalence in 2017 was $25.6 \%$ in men and $18.8 \%$ in women (41). It seems that mortality rates and severe outcomes are more frequent in males. Beside higher prevalence of smoking in men, another possible explanation might be the better personal hygiene in women, and sexual dimorphism. Women can also depend on the protecting estrogen immune-stimulating effect of the immune system (42). However, looking at the data of patients with COVID-19 from China, this explanation does not correlate with the distribution of severe cases (41.9\% in women and $42.2 \%$ in men) (23).

\section{Gender-Related Smoking Particularities}

Country particularities may partially explain the gender differences seen in a smoking habit. China is one of the countries with certain particularities in differences observed between male and female smoking prevalence, and also for COVID-19, male smokers seem to be more prevalent than females. This country may correlate COVID-19 epidemiological data with national studies already conducted in the previous years concerning smoking prevalence. In 1970, 68\% of Chinese men were smokers (including those who had stopped due to health problems), and another $7 \%$ were ex-smokers (described as smokers that stopped by choice). In 1991, with a follow-up until December 31, 1999, there was another Chinese study published (43). There were fewer female smokers than male smokers, but there was a large intergenerational decrease in the female smoking prevalence, from about $10 \%$ prevalence in women born in the 1930s, to only about $1 \%$ in women born around the 1970s $(44,45)$. In the 2015 results, these differences were maintained; however, exposure to secondhand smoke had a prevalence of $27.7 \%$ in the general population (52.1\% among men and $2.7 \%$ among women) (46). These differences may explain why female Chinese smokers seem to be less affected by COVID-19 than male smokers.

\section{Smoking-Cessation Programs in COVID-19 Pandemic Times}

Is there any increased interest in smoking cessation during the first months of the COVID-19 pandemic? On the basis of different studies, it seems that there is no increase in the number of searches for smoking cessation (for both genders) on Google in the initial months of the COVID-19 pandemic. This could indicate that there has been no actual increase in smoking cessation during the pandemic (47). This is in contrast with the recommendations stipulated by Verall, according to whom, to optimize current health-cease (reduce) smoking, alongside the assurance of adequate hypertension and diabetes control and continue exercising, are in the frontline of commonly available and inexpensive immunomodulatory and anti-inflammatory medications for COVID-19 (48). Even though the role of vaping in virus susceptibility is yet to be determined, it is worth saying that vaping should not be seen as a safe alternative, and ecigarettes in general have been shown to be of no help in smoking cessation (49). Another common problem for both genders, also affecting cessation desire, needs to be outlined. The tobacco industry uses subversive tactics to improve its image through corporate social responsibility activities $(50,51)$ 
covering subjects like the potential development of a tobaccoleaves-based vaccine against COVID-19 by British American Tobacco, studies claiming that nicotine has a protective effect against COVID-19 (17, 52). Even though we have no studies on smoking cessation in COVID-19 pandemic, trials from the surgical literature $(53,54)$ suggest that even 4 weeks of smoking cessation may decrease the risk of adverse outcomes and intubation. One of the recommendations of the World Health Organization, for smokers, in this period, is to quit this dependency (55). Stress and worsening of mental health, associated with this pandemic, are well-known predisposing factors for increase in smoking (quantity and frequency) as well as relapses (56). The COVID-19 pandemic disrupted ongoing clinical trials of smoking cessation and forced research teams to rapidly implement changes to assure access to counseling and monitoring by phone or internet communication tools $(57,58)$. Smoking cessation recovers airway ciliary clearance and immune function, being strongly encouraged as a public health measure to limit the global impact of COVID-19 (59).

\section{DISCUSSION}

Adopting simple lifestyle changes could lower the risk of severe forms of COVID-19. This is valid for both genders. We need clear messages for women concerning smoking, with well-defined strategies like those coming from English specialists: advice on how to avoid going back to increased smoking, to fight using fast-acting nicotine replacement products (nicotine gums, mouth sprays), or uptitrating on nicotine by dual use (combinations of short- and long-acting nicotine replacement therapy, and/or e-cigarettes) (60). These messages might also be targeted to some specific ethnic groups (black and south Asian people) and adapted for those with least advantaged socioeconomic status or

\section{REFERENCES}

1. Phelan AL, Katz R, Gostin LO. The novel coronavirus originating in Wuhan, China: challenges for global health governance. JAMA. (2020) 323:70910. doi: 10.1001/jama.2020.1097

2. Qiu F, Liang CL, Liu H, Zeng YQ, Hou S, Huang S, et al. Impacts of cigarette smoking on immune responsiveness: up and down or upside down? Oncotarget. (2017) 8:268-84. doi: 10.18632/oncotarget.13613

3. Cai G. Bulk and single-cell transcriptomics identify tobacco-use disparity in lung gene expression of ACE2, the receptor of 2019-nCov. MedRxiv. (2020) 2020:2020020051. doi: 10.20944/preprints202002.0051.v3. [Epub ahead of print]

4. Park JE, Jung S, Kim A, Park JE. MERS transmission and risk factors: a systematic review. BMC Pub Health. (2018) 18:574. doi: 10.1186/s12889-018-5484-8

5. Arcavi L, Benowitz NL. Cigarette smoking and infection. Arch Intern Med. (2004) 164:2206-16. doi: 10.1001/archinte.164.20.2206

6. Cattaruzza MS, Zagà V, Gallus S, D’Argenio P, Gorini G. Tobacco smoking and COVID-19 pandemic: old and new issues. A summary of the evidence from the scientific literature. Acta Biomed. (2020) 91:10612. doi: 10.23750/abm.v91i2.9698

7. Abate BB, Kassie AM, Kassaw MW, Aragie TG, Masresha SA. Sex difference in coronavirus disease (COVID-19): a systematic review and meta-analysis. BMJ Open. (2020) 10:e040129. doi: 10.1136/bmjopen-2020-040129 educational level, as these groups seem to be more affected by this infection $(61,62)$.

There are currently no peer-reviewed studies published to assess the risk of SARS-CoV-2 infection among smokers in general, and in particular in women. Therefore, a well-designed population-based studies controlled for age, gender, and relevant underlying risk factors must be conducted. There are also several limitations of clinical protocols, including poor data quality and access to hospital data (63). More research is needed to clarify the relationship between smoking and COVID19, and also a focus on the presence of women in these study populations. There is also a need for more evidence on the effect of passive smoking on the spread of SARS$\mathrm{CoV}-2$ infection. For both genders, future studies that test similarly large study populations reflecting the smoking habit rates described in the general population in COVID-19 patients are necessary. In this research, it is also important not to neglect and to identify asymptomatic cases and cases with mild symptoms that do not require hospital visits (64). The impact of smoking in women, during this COVID-19 pandemic, is not sufficiently studied.

\section{AUTHOR CONTRIBUTIONS}

FM: conceptualization, writing original draft, and review. A-GR and R-MR: resources, writing review, and editing. All authors contributed to the article and approved the submitted version.

\section{ACKNOWLEDGMENTS}

We would like to thank Editage (www.editage.com) for English language editing.

8. Simons D, Shahab L, Brown J, Perski O. The association of smoking status with SARS-CoV-2 infection, hospitalisation and mortality from COVID-19: a living rapid evidence review with Bayesian meta-analyses (version 7). Addiction. (2020) 2020:10.1111/add.15276. doi: 10.32388/UJR2AW.8

9. Farsalinos K, Angelopoulou A, Alexandris N, Poulas K. COVID19 and the nicotinic cholinergic system. Eur Respir J. (2020) 56:2001589. doi: 10.1183/13993003.01589-2020

10. Rossato M, Russo L, Mazzocut S, Di Vincenzo A, Fioretto P, Vettor R. Current smoking is not associated with COVID-19. Eur Respir J. (2020) 55:2001290. doi: 10.1183/13993003.01290-2020

11. Patanavanich R, Glantz SA. Smoking is associated with COVID19 progression: a meta-analysis. Nicotine Tob Res. (2020) 22:1653-6. doi: 10.1093/ntr/ntaa082

12. Jiménez-Ruiz CA, López-Padilla D, Alonso-Arroyo A, Aleixandre-Benavent R, Solano-Reina S, de Granda-Orive JI. COVID-19 and smoking: a systematic review and meta-analysis of the evidence. Arch Bronconeumol. (2020) 25:S0300-2896(20)30236-2. doi: 10.1016/j.arbres.2020.06.024

13. Del Sole F, Farcomeni A, Loffredo L, Carnevale R, Menichelli D, Vicario T, et al. Features of severe COVID-19: A systematic review and meta-analysis. Eur J Clin Invest. (2020) 50:e13378. doi: 10.1111/eci. 13378

14. Chow N, Fleming-Dutra K, Gierke R, Hall A, Hughes M, Pilishvili T, et al. Preliminary estimates of the prevalence of selected underlying health conditions among patients with coronavirus disease 2019 - United States, 
February 12-March 28, 2020. MMWR Morb Mortal Wkly Rep. (2020) 69:3826. doi: $10.15585 / \mathrm{mmwr} . \mathrm{mm} 6913 \mathrm{e} 2$

15. Zhang JJ, Dong X, Cao YY, Yuan YD, Yang YB, Yan YQ, et al. Clinical characteristics of 140 patients infected with SARS-CoV-2 in Wuhan, China. Allergy. (2020) 75:1730-41. doi: 10.1111/all.14238

16. Gao Z, Xu Y, Sun C, Wang X, Guo Y, Qiu S, et al. A systematic review of asymptomatic infections with COVID-19. J Microbiol Immunol Infect. (2020) 54:12-8. doi: 10.1016/j.jmii.2020.05.001

17. Changeux JP, Amoura Z, Rey F, Miyara M. A nicotinic hypothesis for COVID19 with preventive and therapeutic implications. Comptes Rendus Biol. (2020) 343:33-9. doi: 10.5802/crbiol.8

18. Miyara M, Tubach F, Amoura Z. Low incidence of daily active tobacco smoking in patients with symptomatic COVID-19 infection. Qeios. (2020) 2020:1-13. doi: 10.32388/WPP19W

19. Gilmore AB, Hird T, Zatonski M. (2020). Overview of Controversial French Studies on Link Between Smoking and COVID-19. Available online at: https://exposetobacco.org/wp-content/uploads/STP043_Covid19_ FrenchStudies_03-1.pdf (accessed November 24, 2020).

20. Abdel Massih AF, Ye J, Kamel A, Mishriky F, Ismail HA, Ragab HA, et al. A multicenter consensus: a role of furin in the endothelial tropism in obese patients with COVID-19 infection. Obes Med. (2020) 19:100281. doi: 10.1016/j.obmed.2020.100281

21. Alqahtani JS, Oyelade T, Aldhahir AM, Alghamdi SM, Almehmadi M, Alqahtani AS, et al. Prevalence, severity and mortality associated with COPD and smoking in patients with COVID-19: a rapid systematic review and metaanalysis. PLoS ONE. (2020) 15:e0233147. doi: 10.1371/journal.pone.0233147

22. Emami A, Javanmardi F, Pirbonyeh N, Akbari A. Prevalence of underlying diseases in hospitalized patients with COVID-19: a systematic review and meta-analysis. Arch Acad Emerg Med. (2020) 8:e35. doi: 10.1371/journal.pone.0241265

23. Guan WJ, Ni ZY, Hu Y, Liang WH, Ou CQ, He JX, et al. Clinical characteristics of coronavirus disease 2019 in China. N Engl J Med. (2020) 382:170820. doi: 10.1056/NEJMoa2002032

24. Lassale C, Gaye B, Hamer M, Gale CR, Batty GD. Ethnic disparities in hospitalization for COVID-19 in England: the role of socioeconomic factors, mental health, and inflammatory and pro-inflammatory factors in a community-based cohort study. Brain Behav Immun. (2020) 88: 449. doi: 10.1016/j.bbi.2020.05.074

25. Hamer M, Kivimäki $M$, Gale CR, Batty GD. Lifestyle risk factors for cardiovascular disease in relation to COVID-19 hospitalization: a community-based cohort study of 387,109 adults in UK. MedRxiv. (2020) 2020:2020.05.09.20096438. doi: 10.1101/2020.05.09.2009 6438

26. Petrilli CM, Jones SA, Yang J, Rajagopalan H, O’Donnell L, Chernyak Y, et al. Factors associated with hospital admission and critical illness among 5279 people with coronavirus disease 2019 in New York City: prospective cohort study. BMJ. (2020) 369:m1966. doi: 10.1136/bmj.m1966

27. Wu Z, McGoogan JM. Characteristics of and important lessons from the coronavirus disease 2019 (COVID-19) outbreak in China: summary of a report of 72,314 cases from the Chinese Center for Disease Control and Prevention. JAMA. (2020) 323:1239-42. doi: 10.1001/jama.2020.2648

28. Huang C, Wang Y, Li X, Ren L, Zhao J, Hu Y, et al. Clinical features of patients infected with 2019 novel coronavirus in Wuhan, China. Lancet. (2020) 395:497-506. doi: 10.1016/S0140-6736(20)30183-5

29. Clark A, Jit M, Warren-Gash C, Guthrie B, Wang HHX, Mercer SW, et al. Global, regional, and national estimates of the population at increased risk of severe COVID-19 due to underlying health conditions in 2020: a modelling study. Lancet Glob Health. (2020) 8: E100317. doi: 10.1016/S2214-109X(20)30264-3

30. Vardavas C, Nikitara K. COVID-19 and smoking: a systematic review of the evidence. Tob Induc Dis. (2020) 18:20. doi: 10.18332/tid/119324

31. Gianfrancesco M, Hyrich KL, Al-Adely S, Carmona L, Danila MI, Gossec L, et al. On behalf of the COVID-19 Global Rheumatology Alliance. Characteristics associated with hospitalisation for COVID-19 in people with rheumatic disease: data from the COVID-19 Global Rheumatology Alliance physician-reported registry. Ann Rheum Dis. (2020) 79:85966. doi: 10.1136/annrheumdis-2020-217871
32. Lippi G, Henry BM. Active smoking is not associated with severity of coronavirus disease 2019 (COVID-19). Eur J Intern Med. (2020). 75:1078. doi: 10.1016/j.ejim.2020.03.014

33. Sanchez-Ramirez DC, Mackey D. Underlying respiratory diseases, specifically COPD, and smoking are associated with severe COVID-19 outcomes: a systematic review and meta-analysis. Respir Med. (2020) 171:106096. doi: 10.1016/j.rmed.2020.106096

34. Reddy RK, Charles WN, Sklavounos A, Dutt A, Seed PT, Khajuria A. The effect of smoking on COVID-19 severity: a systematic review and meta-analysis. $J$ Med Virol. (2020) 93:1045-56. doi: 10.1002/jmv.26389

35. Ojo AS, Balogun SA, Williams OT, Ojo OS. Pulmonary fibrosis in COVID-19 survivors: Predictive factors and risk reduction strategies. Pulm Med. (2020) 2020:6175964. doi: 10.1155/2020/6175964

36. Agrawal H, Das N, Nathani S, Saha S, Saini S, Kakar SS, et al. An assessment on impact of COVID-19 infection in a gender specific manner. Stem Cell Rev Rep. (2020) 17:94-112. doi: 10.1007/s12015-020-10048-z

37. The Open SAFELY Collaborative. Williamson E, Walker AJ, Bhaskaran KJ, Bacon S, Bates C, Morton CE, et al. OpenSAFELY: factors associated with COVID-19-related hospital death in the linked electronic health records of 17 million adult NHS patients. MedRxiv. (2020). doi: 10.1101/2020.05.06.20092999. [Epub ahead of print]

38. World Health Organization. Report of the WHO-China Joint Mission on Coronavirus Disease 2019 (COVID-19). Geneva: WHO. (2020). Available online at: https://www.who.int/docs/default-source/coronaviruse/whochina-joint-mission-on-covid-19-final-report.pdf (accessed April 14, 2020).

39. World Health Organization. WHO Report on the Global Tobacco Epidemic 2019. Geneva: WHO. (2020). Available online at: https://www.who.int/ tobacco/global_report/en/ (accessed April 14, 2020).

40. European Center for Disease Prevention and Control. Coronavirus Disease 2019 (COVID-19) Pandemic: Increased Transmission in the EU/EEA and the UK - seventh update. Stockholm: ECDC (2020). Available online at: https://www.ecdc.europa.eu/sites/default/ files/documents/RRA-seventhupdate-Outbreak-of-coronavirus-disease-COVID-19.pdf (accessed April 14, 2020).

41. Vázquez JC, Redolar-Ripoll D. COVID-19 outbreak impact in Spain: a role for tobacco smoking? Tob Induc Dis. (2020) 18:30. doi: 10.18332/tid/120005

42. Taneja V. Sex hormones determine immune response. Front Immunol. (2018) 9:1931. doi: 10.3389/fimmu.2018.01931

43. Niu SR, Yang GH, Chen ZM, Wang JL, Wang GH, He XZ, et al. Emerging tobacco hazards in China: 2 . Early mortality results from a prospective study. BMJ. (1998) 317:1423-24. doi: 10.1136/bmj.317.7170.1423

44. Chen ZM, Lee LM, Chen JS, Collins R, Wu F, Guo Y, et al. Cohort profile: the Kadoorie Study of Chronic Disease in China (KSCDC). Int J Epidemiol. (2005) 34:1243-9. doi: 10.1093/ije/dyil74

45. Chen ZM, Chen J, Collins R, Guo Y, Peto R, Wu F, et al. China Kadoorie Biobank of 0.5 million people: survey methods, baseline characteristics and long-term follow-up. Int J Epidemiol. (2011) 40:165266. doi: 10.1093/ije/dyr120

46. Parascandola M, Xiao L. Tobacco, and the lung cancer epidemic in China. Transl Lung Cancer Res. (2019) 8(Suppl 1):S2130. doi: $10.21037 /$ tlcr.2019.03.12

47. Heerfordt C, Heerfordt IM. Has there been an increased interest in smoking cessation during the first months of the COVID-19 pandemic? A Google Trends study. Public Health. (2020) 183:6-7. doi: 10.1016/j.puhe.2020.04.012

48. Verrall GM. Scientific rationale for a bottom-up approach to target the host response in order to try and reduce the numbers presenting with adult respiratory distress syndrome associated with COVID-19. Is there a role for statins and COX-2 inhibitors in the prevention and early treatment of the disease? Front Immunol. (2020) 11:2167. doi: 10.3389/fimmu.2020.02167

49. McAlinden KD, Eapen MS, Lu W, Sharma P, Sohal SS. The rise of electronic nicotine delivery systems and the emergence of electronic-cigarettedriven disease. Am J Physiol Lung Cell Mol Physiol. (2020) 319:L58595. doi: 10.1152/ajplung.00160.2020

50. Global Center for Good Governance in Tobacco Control. Tobacco Industry's COVID Donations vs Economic Cost of Tobacco. (2020). Available online at: https://ggtc.world/2020/04/23/tobacco-industrys-covid-donationsvs-economic-cost-of-tobacco/ (accessed May 4, 2020). 
51. Zatonski M, Gilmore AB, Hird TR. The two faces ot the tobacco industry during the COVID-19 Pandemic. (2020). Available online at: https://blogs. bmj.com/tc/2020/05/10/the-two-faces- of-the-tobacco-industry-during-thecovid-19-pandemic/ (accessed November 24, 2020).

52. Girvalaki C, Mechili E, Loghin C, Filippidis F. Social responsibility during the COVID-19 pandemic: tobacco industry's Trojan horse in Europe. Tob Prev Cessation. (2020) 6:37. doi: 10.18332/tpc/123244

53. Wong J, Lam DP, Abrishami A, Chan MT, Chung F. Short-term preoperative smoking cessation and postoperative complications: a systematic review and meta-analysis. Can J Anaesth. (2012) 59:268-79. doi: 10.1007/s12630-011-9652-x

54. Eisenberg SL, Eisenberg MJ. Smoking cessation during the COVID-19 epidemic. Nicotine Tob Res. (2020) 22:1664-5. doi: 10.1093/ntr/ntaa075

55. World Health Organization Statement: Tobacco use and COVID-19. (2020). Available online at: https://www.who.int/news-room/detail/11-052020-who-statement-tobacco-use-and-covid-19 (accessed July 14, 2020).

56. Stubbs B, Veronese N, Vancampfort DA, Prina AM, Lin PY, Tseng PT, et al. Perceived stress and smoking across 41 countries: a global perspective across Europe, Africa, Asia, and the Americas. Sci Rep. (2017) 7:7597. doi: 10.1038/s41598-017-07579-w

57. Mahoney MC, Ashare R, Schlienz N, Duerr C, Hawk LW. Making lemonade from SARS coronavirus-2 lemons: transitioning a smoking cessation trial to a virtual platform. J Subst Abuse Treat. (2020) 117:108100. doi: 10.1016/j.jsat.2020.108100

58. Lang AE, Yakhkind A. Coronavirus disease 2019 and smoking: how and why we implemented a tobacco treatment campaign. Chest. (2020) 158:17706. doi: 10.1016/j.chest.2020.06.013

59. Komiyama M, Hasegawa K. Smoking cessation as a public health measure to limit the coronavirus disease 2019 pandemic. Eur Cardiol. (2020) 15:e16. doi: 10.15420/ecr.2020.11

60. Patwardhan P. COVID-19: risk of increase in smoking rates among England's 6 million smokers and relapse among England's 11 million ex-smokers.
BJGP Open. (2020) 4:bjgpopen20X101067. doi: 10.3399/bjgpopen20X1 01067

61. Niedzwiedz CL, O'Donnell CA, Jani BD, Demou E, Ho FK, Celis-Morales $\mathrm{C}$, et al. Ethnic and socioeconomic differences in SARS-CoV-2 infection: prospective cohort study using UK Biobank. BMC Med. (2020) 18:160. doi: 10.1186/s12916-020-0 1640-8

62. de Lusignan S, Dorward J, Correa A, Jones N, Akinyemi O, Amirthalingam $\mathrm{G}$, et al. Risk factors for SARS-CoV-2 among patients in the Oxford Royal College of General Practitioners Research and Surveillance Centre primary care network: a cross-sectional study. Lancet Infect Dis. (2020) 20:103442. doi: 10.1016/S1473-3099(20)30371-6

63. World Health Organization. Smoking and COVID-19. Scientific Brief. (2020). Available online at: https://apps.who.int/iris/bitstream/handle/10665/332182/ WHO-2019-nCoV-Sci_Brief-Smoking-2020.1-eng.pdf (accessed July 14, 2020).

64. International Union Against Tuberculosis and Lung Disease (The Union). COVID-19 and Tobacco: The Union's Scientific Brief. (2020). Available online at: https://www.theunion.org/sites/default/files/2021-03/Master\%Brief \%201\%20March\%202021_0.pdf (accessed April 20, 2021).

Conflict of Interest: The authors declare that the research was conducted in the absence of any commercial or financial relationships that could be construed as a potential conflict of interest.

Copyright (C) 2021 Mihaltan, Rajnoveanu and Rajnoveanu. This is an open-access article distributed under the terms of the Creative Commons Attribution License (CC $B Y)$. The use, distribution or reproduction in other forums is permitted, provided the original author(s) and the copyright owner(s) are credited and that the original publication in this journal is cited, in accordance with accepted academic practice. No use, distribution or reproduction is permitted which does not comply with these terms. 